\title{
Medication-Related Hospital Readmissions Within 30 Days of Discharge: Prevalence, Preventability, Type of Medication Errors and Risk Factors
}

\author{
Elien B. Uitvlugt ${ }^{1}$, Marjo J. A. Janssen ${ }^{1}$, Carl E. H. Siegert ${ }^{2}$, Eva L. Kneepkens ${ }^{1}$, \\ Bart J. F. van den Bemt ${ }^{3,4}$, Patricia M. L. A. van den Bemt ${ }^{5}$ and Fatma Karapinar-Çarkit ${ }^{1 *}$ \\ ${ }^{1}$ Onze Lieve Vrouwe Gasthuis OLVG, Department of Hospital Pharmacy, Amsterdam, Netherlands, ${ }^{2}$ Onze Lieve Vrouwe Gasthuis \\ OLVG, Department of Internal Medicine, Amsterdam, Netherlands, ${ }^{3}$ Department of Pharmacy, Sint Maartenskliniek, Nijmegen, \\ Netherlands, ${ }^{4}$ Department of Pharmacy, Radboud University Medical Centre, Nijmegen, Netherlands, ${ }^{5}$ Department of Clinical \\ Pharmacy and Pharmacology, University Medical Center Groningen, Groningen, Netherlands
}

OPEN ACCESS

Edited by:

Jean Paul Deslypere, Aesculape CRO, Belgium

Reviewed by: Johannes P. Mouton, University of Cape Town, South Africa Kiguba Ronald, Makerere University, Uganda

*Correspondence:

Fatma Karapinar-Çarkıt f.karapinar@olvg.nl

Specialty section: This article was submitted to Pharmaceutical Medicine and

Outcomes Research,

a section of the journal Frontiers in Pharmacology

Received: 29 May 2020 Accepted: 11 February 2021

Published: 13 April 2021

Citation:

Uitvlugt $E B$, Janssen $M J A$, Siegert CEH, Kneepkens EL,

van den Bemt BJ F,

van den Bemt PMLA and Karapinar-Carkit $F$ (2021) MedicationRelated Hospital Readmissions Within

30 Days of Discharge: Prevalence, Preventability, Type of Medication

Errors and Risk Factors.

Front. Pharmacol. 12:567424. doi: 10.3389/fphar.2021.567424
Background: Hospital readmission rates are increasingly used as a measure of healthcare quality. Medicines are the most common therapeutic intervention but estimating the contribution of adverse drug events as a cause of readmissions is difficult.

Objectives: To assess the prevalence and preventability of medication-related readmissions within 30 days after hospital discharge and to describe the risk factors, type of medication errors and types of medication involved in these preventable readmissions.

Design: A cross-sectional observational study.

Setting: The study took place across the cardiology, gastroenterology, internal medicine, neurology, psychiatry, pulmonology and general surgery departments in the OLVG teaching hospital, Netherlands.

Participants: Patients with an unplanned readmission within 30 days after discharge from an earlier hospitalization (index hospitalization: $\Vdash$ ) were reviewed.

Measurements: The prevalence and preventability of medication-related readmissions were assessed by residents in multidisciplinary meetings. A senior internist and hospital pharmacist reassessed the prevalence and preventability of identified cases. Generalized estimating equation with logistic regression was performed to identify risk factors of potentially preventable medication-related readmissions.

Results: Of 1,111 included readmissions, 181 (16\%) were medication-related, of which 72 (40\%) were potentially preventable. The number of medication changes at IH (Adjusted odds ratio [OR adj] $1.14 ; 95 \% \mathrm{Cl}: 1.05-1.24)$ and having $\geq 3$ hospitalizations 6 months before $\mathrm{IH}$ (ORadj: 2.11 ; 95\% Cl: 1.12-3.98) were risk factors of a preventable medicationrelated readmission. Of these preventable readmissions, 35\% were due to prescribing errors, 35\% by non-adherence and $30 \%$ by transition errors. Medications most frequently involved were diuretics and antidiabetics. 
Conclusion: This study shows that $16 \%$ of readmissions are medication-related, of which $40 \%$ are potentially preventable. If the results are confirmed in larger multicentre studies, this may indicate that more attention should be paid to medication-related harm in order to lower the overall readmission rates.

Keywords: readmission, ADEs, quality of care, medication related problem, transitions in care

\section{INTRODUCTION}

Unplanned hospital readmissions within 30 days are increasingly used as a measure of healthcare quality. Previous studies show that approximately $20 \%$ of patients discharged from hospital are readmitted within 30 days of discharge (Jencks et al., 2009) and $5-79 \%$ of those readmissions are estimated to be preventable (median: 27\%) (Van Walraven et al., 2011). Medication, and more specifically polypharmacy, seems to be one of the causes for these readmissions (Garcia-Caballos et al., 2010; Ahmad et al., 2014). It is estimated that $21 \%$ (range: $3-64 \%$ ) of readmissions are due to medication and a median of $69 \%$ (range: $5-87 \%$ ) of these readmissions were deemed preventable (El Morabet et al., 2018). However, previous studies on the impact of medication on (preventable) hospital readmissions have some methodological flaws (El Morabet et al., 2018). The wide range of point estimates found in previous studies may be due to the small sample size of the reviewed studies, the inclusion of only one department and the method to assess preventability (i.e., by either a pharmacist or physician, not both). Consequently, it is difficult to state how often medication-related readmissions occur. Only six studies have determined the preventability of medication-related readmissions and in only two of these was the preventability assessed by a multidisciplinary method (Ruiz et al., 2008; Rothwell et al., 2011), despite the fact that a multidisciplinary review is recommended (van Doormaal et al., 2008). Furthermore, the type of medication errors involved in preventable medication-related readmissions were unclear and there is a focus on prescribing errors, whereas other medication errors may also be important, such as non-adherence (El Morabet et al., 2018; Parekh et al., 2018). Thus, a clear understanding of the impact and risk factors for adverse drug events on readmissions is lacking. In order to develop interventions to lower overall readmission rates in hospitals it is important to understand the role that medication plays in patient readmissions because medication is the most common therapeutic intervention (World Health Organisation, 2019). Therefore, this study aims to assess the prevalence and preventability of medication-related readmissions within 30 days of discharge, Additionally, potential risk factors associated with preventable medication-related readmissions, the types of medication errors and the medications involved in those readmissions are assessed.

\section{METHODS}

\section{Study Design and Participants}

The data for this study were collected within the context of a larger study on all-cause readmissions (van der Does et al., 2020). The all- cause study and the current study used the same inclusion criteria. The all-cause study assessed the extent to which the provided care during an earlier hospitalization, and the subsequent outpatient follow-up care provided by the hospital, was responsible for the readmission. The current study focused on readmissions due to adverse drug events, which are any injuries resulting from medication use, including physical harm, mental harm, or loss of function (El Morabet et al., 2018, see for definitions Supplementary Material). Adverse drug events can result from (non-preventable) adverse drug reactions (defined as a response to a medicine that is noxious and unintended and occurs at doses normally used in man) (World Health Organization, 2006) or (preventable) medication errors (defined as errors in the process of prescribing, dispensing or administering medication that may cause or lead to inappropriate medication use or harm while the medication is in the control of the healthcare professional, patient or consumer) (van den Bemt and Egberts 2007).

A cross-sectional single-centre observational study was conducted from July 15, 2016 until February 28, 2018 at seven clinical departments in the OLVG teaching hospital in Amsterdam, Netherlands.

All seven clinical departments and the hospital pharmacy assigned a resident to review readmissions. All residents received a group training prior to the start of the study regarding the assessment whether the readmission was caused by healthcare (i.e., causality) and the preventability of readmissions (van der Does et al., 2020). In case of replacement of a resident, the new resident received the same training.

All the reviewers had full access to the hospital information system, including laboratory values, medication prescriptions and all notes (i.e., from nurses, physicians, pharmacy, etc.).

Inclusion criteria were: unplanned readmissions of adult patients ( $\geq 18$ years) within 30 days after discharge from an earlier hospitalization (index hospitalization: $\mathrm{IH}$ ) to one of the participating departments (cardiology, gastroenterology, internal medicine, neurology, psychiatry, pulmonology and general surgery). Those wards were chosen based on the highest readmission rates in previous years.

Exclusion criteria were: patients who were transferred to another hospital during IH, patients who left the hospital against medical advice during $\mathrm{IH}$ and if the readmission was due to attempted suicide. Furthermore, a readmission was excluded if it was deemed unrelated to the IH. This was initially assessed by the study coordinator (a medical doctor) and then double-checked by the resident of the department of $\mathrm{IH}$. Any non-agreement between the two led to the case being discussed at a multidisciplinary meeting (see Figure 1).

The study was approved by the local review board of the hospital (Advies Commissie Wetenschappelijk Onderzoek 


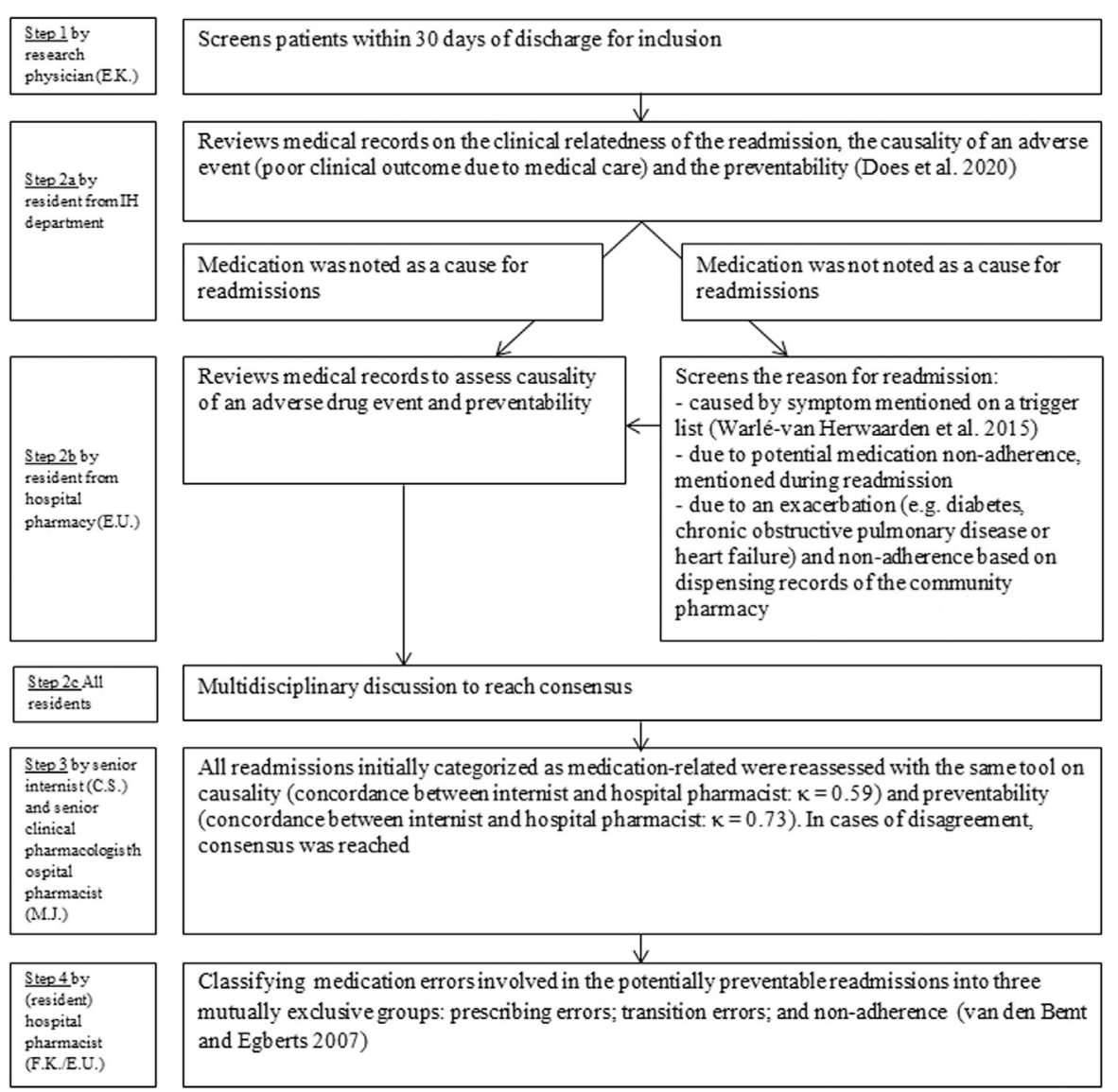

FIGURE 1 | Assessment of causality, preventability and type of medication errors. An adjusted version of the algorithm by Kramer et al. and a modified version of the algorithm by Schumock and Thornton were used to assess the association between the clinical presentation at readmission and the suspected medication (causality) and preventability (Kramer et al., 1979; Schumock and Thornton. 1992; McDonnell and Jacobs. 2002; Lau et al., 2003; Leendertse et al., 2008). Therapy adherence was defined as a refill rate higher than 0.8 . The refill rate was defined as the number of daily doses dispensed (refill interval) divided by the total number of days between the first and last prescription in this period (we used a period of 8 months before readmission). If the refill rate could not be calculated but the doctor mentioned the patient as being therapy non-adherent, the patient was classified as such. Likewise, a refill rate above 0.8 can be overruled by a doctor classifying the patient as non-adherent.

Medische Ethische Commissie, ACWO-MEC; registration number 16-028). Patient data were obtained and handled in accordance with privacy regulations.

\section{Usual Care During Index Hospitalization}

In the OLVG hospital, medication monitoring is performed by hospital pharmacists using a computerized system to check for the right dose and medication interactions. A Transitional Pharmaceutical Care (TPC) program (Karapinar-Çarkit et al., 2012) was implemented gradually during the study.

- On departments with this TPC program, hospital pharmacy teams performed medication reconciliation upon hospital admission and discharge using the dispensing history of the community pharmacy and information from the patient/ carer. Any discrepancies between a patient's actual medication use and the medication prescribed in hospital were discussed with the resident. No formal medication review was performed. However, obvious errors in pharmacotherapy were eliminated: for example, lack of a laxative when an opioid is prescribed or no indication for hypnotics upon discharge and/or addressing a stop date for antibiotics or opioids. The reason for medication changes was explained to the patient during discharge counseling and a written medication summary was provided. The pharmacy team compiled a TPC medication overview that the resident could upload into the discharge letter to the general practitioner.

- On departments where the TPC program was not yet implemented, residents and nurses were responsible for assessing the patient's actual medication use by interviewing patients/carers. If regarded as necessary, they could request the hospital pharmacy to obtain a dispensing history from the community pharmacy. At hospital discharge, the resident uploads information from the hospital's prescribing system or types information into the discharge letter to the general practitioner. 


\section{Assessment of Causality, Preventability and Type of Medication Errors}

Figure 1 shows the different steps in the assessment of causality, preventability and type of medication errors.

If medication was noted as a cause for readmissions by the residents, the readmission was included for a review by the resident of the hospital pharmacy. The resident of the hospital pharmacy assessed the causal relationship between the suspected medicine and the reason for readmission (i.e., causality), using an adjusted version of the algorithm of Kramer et al. (1979), see Supplementary Material). This algorithm has been used in a previous study to assess the causality of medication related admissions (HARM-study: Leendertse et al., 2008, see Supplementary Material). This algorithm included three questions: whether the reason for admission is known to be an effect of the suspected medicine, whether alternative causes can explain the relationship between the suspected medicine and the readmission, and whether a plausible time relationship exists between the readmission and the start of medication administration (or the occurrence of the medication error). The subscores of the three questions were added to a total score, and classified as: possible, probable or unlikely causal. Readmissions classified as possible or probable causal were classified as medication related and the preventability of those readmissions was assessed by the same pharmacist according to a modified version of the algorithm by Schumock and Thornton (Schumock and Thornton, 1992; Lau et al., 2003; Leendertse et al., 2008, see Supplementary Material). The algorithm assessed dosing or therapeutic errors (e.g., type of medication inappropriate for the patient's clinical condition, inappropriate dose or frequency, medication contraindicated), inadequate monitoring of the therapy (e.g., therapeutic drug monitoring or other monitoring), lack of preventative measure (e.g., no laxative with opioid use) or incorrect medication use (e.g., non-adherence). A readmission was considered potentially preventable when a medication error caused the readmission (see Supplementary Material). All potentially preventable readmissions were discussed in multidisciplinary meetings with all residents to reach consensus.

Hereafter all medication-related readmissions were reassessed by a senior internist and senior clinical pharmacologist/hospital pharmacist. The agreement between internist and hospital pharmacist for medication-relatedness's was $\kappa=0.59$ (moderate) and for preventability $\kappa=0.73$ (substantial). In case of disagreement, consensus was reached.

Finally, medication errors involved in potentially preventable readmissions were classified by the resident of the hospital pharmacy and the principal investigator/hospital pharmacist into three mutually exclusive groups to determine where in the medication process the error has occurred. These groups included: prescribing errors (defined as dosing/therapeutic errors or inadequate monitoring); transition errors (insufficient communication to the patient and/or next healthcare provider, e.g., regarding a medication change); and non-adherence (medication not used as prescribed by the patient), according to the van den Bemt and Egberts classification (van den Bemt and Egberts, 2007).

\section{Data Collection}

Relevant information on included readmissions was collected from medical records and entered into a data processing program (Castor EDC). Potential risk factors were collected based on previous studies (Van Walraven et al., 2011; Feigenbaum et al., 2012; van der Does et al., 2020) (Table 1).

The updated Charlson comorbidity score (Quan et al., 2011) was derived from the hospital data system. Renal function was calculated using the Chronic Kidney disease Epidemiology Collaboration (CKD-EPI) formula. A cut-off of $50 \mathrm{ml} / \mathrm{min} / 1.73 \mathrm{~m}^{2}$ was chosen based on the Dutch guidelines for dose adjustments in renal impairment. The presence of a language barrier was determined based on notes from the resident or nurse in the electronic patient file (e.g., use of an interpreter, difficulties in asking the medical history). After completion of the data entry the data were visually checked with histograms and scatterplots to check extreme values and missing data.

\section{Main Outcome Measures}

The prevalence of medication-related readmissions (defined as the number of medication-related readmissions divided by the total number of unplanned readmissions) and the percentage of potentially preventable medication-related readmissions (defined as the number of potentially preventable medication-related readmissions divided by the total number of medicationrelated readmissions) were the main outcome measures. Additionally, the following measures for potentially preventable medication-related readmissions were assessed: potential risk factors (Table 1), type of medication and medication error that were involved.

\section{Data Analysis}

Statistical analysis was performed in SPSS version 22.0 (IBM SPSS, Chicago, IL, United States). Categorical variables are reported as percentages. Normally and non-normally distributed continuous variables are reported as mean with standard deviation (SD) and median with interquartile range (IQR), respectively. To identify potential risk factors of potentially preventable medication-related readmissions and to adjust for patients with multiple readmissions, a univariate generalized estimating equation (GEE) with logistic regression was performed. Parameters with a p-value $<0.10$ in the univariate analysis were entered into a multivariable model (Steyenberg. 2009 Edition). P-values lower than 0.05 were considered statistically significant. We checked for presence of collinearity $(R>0.5)$, reported unadjusted odds ratios (OR), adjusted odds ratios $\left(\mathrm{OR}_{\mathrm{adj}}\right)$ and $95 \%$ confidence intervals (CI). No pairwise correlations were above 0.5 .

\section{RESULTS}

\section{Prevalence and Preventability}

Of the 1,356 readmissions screened, 245 (18\%) were excluded (see Figure 2). This resulted in the inclusion of 1,111 readmissions for 873 unique patients: 699 patients had one readmission and 174 patients had two or more. 
TABLE 1 | Patient- and index hospitalization-related parameters and adjusted odds ratios and 95\% confidence intervals from parameters significantly associated in the univariate analyses.

\begin{tabular}{|c|c|c|c|c|c|c|}
\hline & $\begin{array}{c}\text { Medication-related and potentially } \\
\text { preventable } N=72\end{array}$ & $\begin{array}{l}\text { Not medication- } \\
\text { related } N=930\end{array}$ & OR $(95 \% \mathrm{Cl})$ & $\begin{array}{c}p- \\
\text { value }\end{array}$ & $\begin{array}{c}\text { OR }_{\text {adj }} \\
(95 \% \mathrm{Cl})\end{array}$ & $\begin{array}{c}p- \\
\text { value }\end{array}$ \\
\hline \multicolumn{7}{|l|}{ Patient related ${ }^{\mathrm{a}}$} \\
\hline Male, $\mathrm{n}(\%)$ & $38(52.8)$ & $452(48.6)$ & $\begin{array}{c}1.06 \\
(0.53-2.14)\end{array}$ & 0.86 & & \\
\hline Age in years, mean (SD) & $69.5(13.7)$ & $63.4(17.4)$ & $\begin{array}{c}1.02 \\
(1.01-1.04)\end{array}$ & 0.01 & $\begin{array}{c}1.02 \\
(0.99-1.04)\end{array}$ & 0.15 \\
\hline Language barrier present, n (\%) & $25(34.7)$ & $170(18.2)$ & $\begin{array}{c}1.75 \\
(0.95-3.21)\end{array}$ & 0.08 & $\begin{array}{c}1.76 \\
(0.92-3.40)\end{array}$ & 0.09 \\
\hline \multicolumn{7}{|l|}{ Living situation, $\mathrm{n}(\%)$} \\
\hline Living alone & $24(33.3)$ & $278(29.9)$ & $\begin{array}{c}1.13 \\
(0.22-5.69)\end{array}$ & 0.89 & & \\
\hline Living with partner/family & $35(48.6)$ & $488(52.5)$ & $\begin{array}{c}1.42 \\
(0.24-8.53)\end{array}$ & 0.70 & & \\
\hline $\begin{array}{l}\text { Institution (rehabilitation centre or nursing } \\
\text { home) }\end{array}$ & $10(13.8)$ & $110(11.8)$ & & Ref. & & \\
\hline $\begin{array}{l}\text { Number of medicines at discharge } \Vdash \mathrm{H} \text {, } \\
\text { mean (SD) }\end{array}$ & $12.6(5.4)$ & $9.6(5.7)$ & $\begin{array}{c}1.07 \\
(1.04-1.12)\end{array}$ & $<0.01$ & $\begin{array}{c}1.02 \\
(0.96-1.08)\end{array}$ & 0.57 \\
\hline $\begin{array}{l}\text { Number of medication changes during } \mathrm{H}_{\text {, }} \\
\text { median }+\mathrm{IQR}\end{array}$ & $3(2-6)$ & $2(1-4)$ & $\begin{array}{c}1.15 \\
(1.03-1.29)\end{array}$ & 0.02 & $\begin{array}{c}1.14 \\
(1.05-1.24)\end{array}$ & $<0.01$ \\
\hline $0-1, \mathrm{n}(\%)$ & $14(19.4)$ & $323(34.7)$ & & & & \\
\hline $2, \mathrm{n}(\%)$ & $7(9.7)$ & $166(17.8)$ & & & & \\
\hline $3-4, \mathrm{n}(\%)$ & $21(29.2)$ & $257(27.6)$ & & & & \\
\hline$\geq 5, \mathrm{n}(\%)$ & $29(40.3)$ & $173(18.6)$ & & & & \\
\hline eGFR<50 ml/min/1.73 m², n (\%) & $24(33.3)$ & $166(17.8)$ & $\begin{array}{c}1.32 \\
(0.52-3.35)\end{array}$ & 0.56 & & \\
\hline CCl score, median (IQR) & $1(0-3)$ & $1(0-2)$ & $\begin{array}{c}1.07 \\
(0.95-1.21)\end{array}$ & 0.26 & & \\
\hline $0-1, \mathrm{n}(\%)$ & $39(54.1)$ & $593(63.7)$ & & & & \\
\hline $2-3, n(\%)$ & $16(22.2)$ & $206(21.8)$ & & & & \\
\hline$\geq 4, \mathrm{n}(\%)$ & 17 (23.6) & $131(14.1)$ & & & & \\
\hline \multicolumn{7}{|l|}{ IH related } \\
\hline Unplanned IH, n (\%) & $60(83.3)$ & $751(80.7)$ & $\begin{array}{c}1.02 \\
(0.55-1.89)\end{array}$ & 0.94 & & \\
\hline Duration of $I \mathrm{H}$ in days, median + IQR & $7(3-13)$ & $5(2-9)$ & $\begin{array}{c}1.01 \\
(0.99-1.03)\end{array}$ & 0.43 & & \\
\hline $\begin{array}{l}\text { Time between IH and readmission in days, } \\
\text { median + IQR }\end{array}$ & $10.5(4.3-18.9)$ & $9(4-17)$ & $\begin{array}{c}1.01 \\
(0.97-1.06)\end{array}$ & 0.60 & & \\
\hline Discharge on Saturday or Sunday, n (\%) & $11(15.2)$ & $143(15.4)$ & $\begin{array}{c}1.03 \\
(0.44-2.37)\end{array}$ & 0.95 & & \\
\hline $\begin{array}{l}\text { Planned post-discharge outpatient visit, } \\
\text { n (\%) }\end{array}$ & $61(84.7)$ & 792 (85.2) & $\begin{array}{c}1.66 \\
(0.24-11.24)\end{array}$ & 0.61 & & \\
\hline $\begin{array}{l}\geq 3 \text { hospital hospitalizations } 6 \text { months } \\
\text { before } \mathrm{IH}, \mathrm{n}(\%)\end{array}$ & $19(26.4)$ & $118(12.7)$ & $\begin{array}{c}1.66 \\
(0.94-2.95)\end{array}$ & 0.08 & $\begin{array}{c}2.11 \\
(1.12-3.98)\end{array}$ & 0.02 \\
\hline $\begin{array}{l}\geq 2 \text { ED visits (without a hospitalization), } \\
6 \text { months before } I H, n(\%)\end{array}$ & $13(18.1)$ & $70(7.5)$ & $\begin{array}{c}2.01 \\
(1.05-3.86)\end{array}$ & 0.04 & $\begin{array}{c}2.15 \\
(1.00-4.65)\end{array}$ & 0.05 \\
\hline $\begin{array}{l}\text { Discharge letter send to GP after discharge } \\
\mathrm{IH}, \mathrm{n}(\%)\end{array}$ & $61(84.7)$ & $761(81.8)$ & $\begin{array}{c}1.67 \\
(0.83-3.34)\end{array}$ & 0.15 & & \\
\hline $\begin{array}{l}\text { Discharge letter send to GP } \leq 2 \text { days after } \\
\text { discharge } ॥ \mathrm{H}, \mathrm{n}(\%) \\
\text { Department, } \mathrm{n}(\%)\end{array}$ & $22(36.1)$ & $222(29.2)$ & $\begin{array}{c}1.52 \\
(0.94-2.45)\end{array}$ & 0.09 & $\begin{array}{c}1.37 \\
(0.82-2.31)\end{array}$ & 0.23 \\
\hline $\begin{array}{l}\text { Department, } \mathrm{n}(\%) \\
\text { Internal medicine }\end{array}$ & 17 (23.6) & $190(20.4)$ & - & Ref. & & \\
\hline Pulmonology & $11(15.3)$ & 189 (20.3) & $\begin{array}{c}0.59 \\
(0.09-3.72)\end{array}$ & 0.57 & & \\
\hline Cardiology & 17 (23.6) & $113(12.2)$ & $\begin{array}{c}1.12 \\
(0.67-17.49)\end{array}$ & 0.94 & & \\
\hline Surgery & $12(16.7)$ & $264(28.4)$ & $\begin{array}{c}0.45 \\
(0.05-4.02)\end{array}$ & 0.48 & & \\
\hline Gastroenterology & $13(18.0)$ & $125(13.4)$ & $\begin{array}{c}0.52 \\
(0.22-1.22)\end{array}$ & 0.13 & & \\
\hline Neurology ${ }^{b}$ & $2(2.8)$ & $42(4.5)$ & - & - & & \\
\hline Psychiatry $^{\mathrm{b}}$ & 0 & $7(1)$ & - & - & & \\
\hline
\end{tabular}

GP, general practitioner; IH, index hospitalization; IQR, interquartile range; ED, emergency department; eGFR, estimated glomerular filtration rate. a Data were missing for: living situation (5.1\%) and eGFR<50 $\mathrm{ml} / \mathrm{min} / 1.73 \mathrm{~m}^{2}(0.8 \%)$.

${ }^{b}$ Too few cases to include in this analysis. 


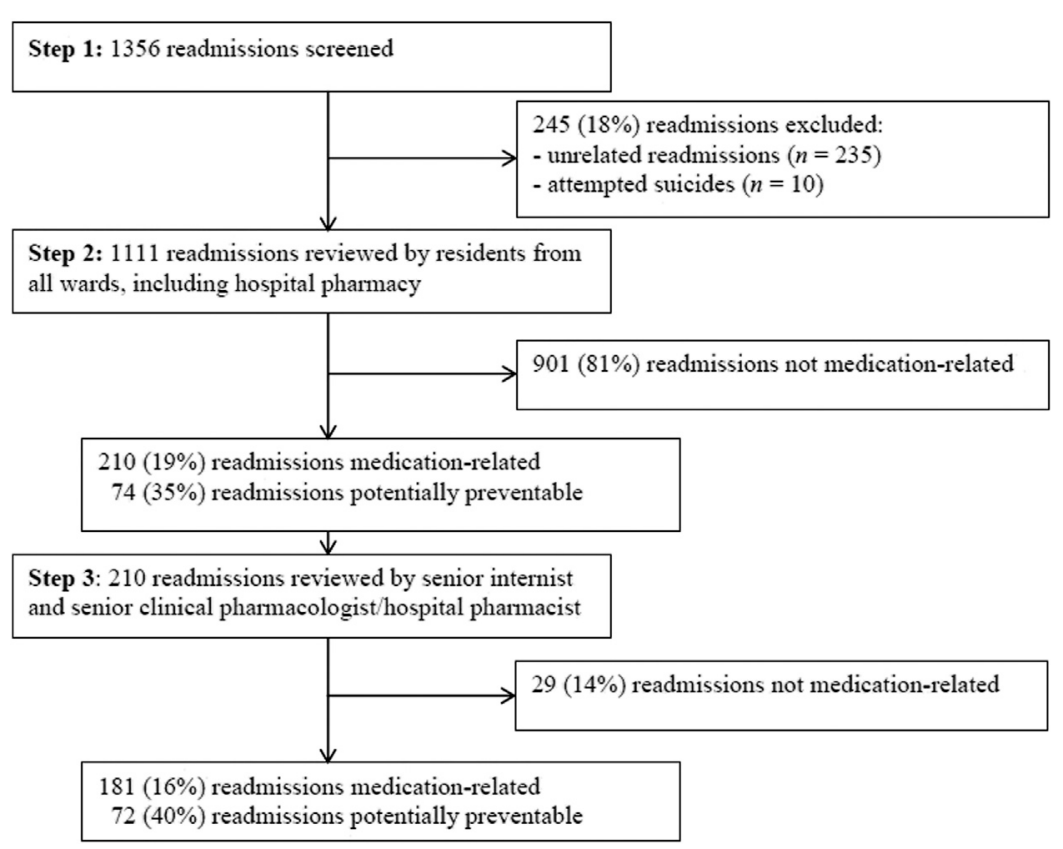

FIGURE 2 | Study flow and main outcome.

Initially, 210 readmissions were considered to be medicationrelated (step 2, Figure 1). After confirmation by a senior internist (C.S.) and senior clinical pharmacologist/hospital pharmacist (M.J.) (step 3, Figure 1), 181 of the 1,111 readmissions (16\%) were considered medication-related, of which 72 (40\%) were assessed as potentially preventable (Figure 2).

\section{Readmission Characteristics and Risk Factors}

Table 1 shows the patient-related and IH-related characteristics of the potentially preventable medication-related readmissions $(n=72)$ vs. non-medication-related readmissions $(n=930)$. Mean age in the potentially preventable group was 69.5 years, $52.8 \%$ were men and the average number of medicines at discharge of the $\mathrm{IH}$ was 12.6.

Parameters independently associated with potentially preventable readmissions were number of medication changes during IH (ORadj: 1.14; 95\% CI: 1.05-1.24) and three or more hospitalizations six months before IH (ORadj: 2.11; 95\% CI: 1.12-3.98) (Table 1).

\section{Types of Medication and Reasons for Potentially Preventable Readmissions}

The top five medications associated with potentially preventable medication-related readmissions were antidiabetics (15\%), diuretics (15\%), laxatives (14\%), antithrombotic agents (10\%) and medications for asthma/chronic obstructive pulmonary disease (COPD) (8\%).

The most common reason for readmissions was cardiovascular symptoms (32\%). Other reasons were poor glycemic control (15\%), liver diseases (14\%), gastrointestinal tract symptoms
(6\%), coagulation disorders $(10 \%)$, respiratory symptoms $(10 \%)$, central nervous system diseases (6\%), electrolyte disturbances (6\%) and infections (3\%) (Table 2).

\section{Medication Errors Involved in Potentially Preventable Readmissions}

Table 3 shows the type of medication errors of the 72 potentially preventable medication-related readmissions. Prescribing errors (35\%) and non-adherence $(35 \%)$ were the most common medication errors. Underprescribing (40\%), wrong dosage (24\%) and inadequate monitoring (20\%) were the most common sub-types of the prescribing errors.

\section{DISCUSSION}

This study shows that $16 \%$ of the readmissions are caused by medication and that $40 \%$ of these are potentially preventable. Most of the medication errors involved in the potentially preventable readmissions were classified as non-adherence (35\%) and prescribing errors (35\%), followed by transition errors (30\%).

The frequency of $16 \%$ found in the current study is comparable to the median of $21 \%$ found in a systematic review of medicationrelated readmissions (El Morabet et al., 2018). Of the medicationrelated readmissions $40 \%$ were considered potentially preventable and the systematic review found that a median of $69 \%$ were preventable. The difference in preventability between studies could be caused by the case-mix of studies (e.g., including only geriatric patients vs. adult patients) and how preventability was assessed (e.g., monodisciplinary or multidisciplinary). 
TABLE 2 | Reasons for potentially preventable medication-related readmissions and the associated medication ${ }^{\mathrm{a}}$.

\begin{tabular}{|c|c|c|}
\hline $\begin{array}{l}\text { Clinical presentation at } \\
\text { readmission }\end{array}$ & $\begin{array}{l}\text { Preventable } \\
\text { readmissions } \\
(n=72,100 \%)\end{array}$ & $\begin{array}{l}\text { Associated medications (no. } \\
\text { Of readmissions) }\end{array}$ \\
\hline \multicolumn{3}{|l|}{ Circulatory } \\
\hline $\begin{array}{l}\text { Cardiovascular symptoms (e.g., heart failure, dysrhythmias, } \\
\text { hyper- or hypotension) } \\
\text { Endocrine system }\end{array}$ & $23(32 \%)$ & $\begin{array}{l}\text { Diuretics (10), calcium antagonists (4), beta-blockers (3), medication affecting RAAS } \\
\text { (3), cardiac glycosides (2), organic nitrates (1), theophylline (1), alpha-blocker (1) }\end{array}$ \\
\hline $\begin{array}{l}\text { Hypoglycemia or hyperglycemia } \\
\text { Gastrointestinal system }\end{array}$ & $11(15 \%)$ & Insulin (7), oral antidiabetics (3), corticosteroids (1) \\
\hline Hepatic encephalopathy/liver failure & $10(14 \%)$ & Laxatives (9), acetaminophen (1) \\
\hline $\begin{array}{l}\text { Gastrointestinal symptoms (diarrhea, constipation) } \\
\text { Blood }\end{array}$ & $4(6 \%)$ & Laxatives (1), loperamide (1), oral antidiabetics (1), antiemetics (1) \\
\hline $\begin{array}{l}\text { Coagulation disorders (e.g., bleeding, anemia, embolism) } \\
\text { Respiratory system }\end{array}$ & $7(10 \%)$ & Anticoagulants (7) \\
\hline $\begin{array}{l}\text { Respiratory symptoms (e.g., dyspnoea) } \\
\text { Central nervous system }\end{array}$ & $6(8 \%)$ & Respiratory medication (5), opioids (1) \\
\hline $\begin{array}{l}\text { Epileptic seizure, pain, dysregulation of Parkinson's disease } \\
\text { Electrolytes }\end{array}$ & $4(6 \%)$ & Opioids (1), antiepileptics (2), anti-Parkinson medication (1) \\
\hline $\begin{array}{l}\text { Electrolyte disturbance (e.g., hyper- or hypokalemia) } \\
\text { Immune system }\end{array}$ & $4(6 \%)$ & Mineral supplements (2), medication for treatment of hyperkalemia (1), diuretics (1) \\
\hline $\begin{array}{l}\text { Infection } \\
\text { Other }\end{array}$ & $2(3 \%)$ & Antibiotics (2) \\
\hline Headache & $1(1 \%)$ & Infliximab (1) \\
\hline
\end{tabular}

${ }^{a}$ More than one medicine per readmission is possible. RAAS, renin-angiotensin-aldosterone system.

The finding that $40 \%$ of the medication-related readmissions were considered to be potentially preventable indicates that improvements may be possible. A total of $35 \%$ of the potentially preventable readmissions were due to prescribing errors, with underprescribing, wrong dosage and inadequate monitoring being the most common. To address underprescribing, a clinical medication review is needed to recognize the undertreated symptoms. To address inadequate monitoring, the clinical medication review should include a monitoring plan as well, describing when and how the effects of medication changes are evaluated and defining the responsibilities of the different care providers involved. Another 35\% of the potentially preventable readmissions were due to medication non-adherence. Most of the previous studies investigating readmissions did not describe this relevant cause (Reynolds et al., 2014; El Morabet et al., 2018). Rosen et al. show that patients with low or intermediate medication adherence had more than 2.5 -fold greater odds of being readmitted within 30 days (Rosen et al., 2017). However, non-adherence is a multifaceted problem (Kardas et al., 2013). The question is whether medication adherence is a modifiable predictor of hospital readmissions or a measure for underlying causes, such as socioeconomic, condition- or therapy-related factors, which are the true causes for readmission (Sabaté 2003). This is an important issue for future research. The final $30 \%$ of the potentially preventable readmissions were due to transition errors, including failure to communicate medication changes to the patient and/or the next healthcare providers. It remains a challenge to communicate medication changes after discharge, despite the efforts made in recent years to improve the transfer of medication-related information, including the implementation of medication reconciliation (Mueller et al., 2012). Interventions across the settings are needed, with specific recommendations to the patient and the next healthcare provider on what should be done after discharge. The study by Ravn-Nielsen et al. showed that a transitional pharmacist intervention, based on medication review, medication reconciliation, motivational interviews and follow-up after discharge, resulted in a significant reduction in the number of patients readmitted within 30 days (Ravn-Nielsen et al., 2018). The intensity of this intervention could explain its effectiveness. To implement such labor-intensive interventions in an effective way, a focus on patients at risk of adverse drug events is needed. The potential risk factors identified in this study might help to select these patients. A higher number of medication changes during $\mathrm{IH}$ and three or more hospital hospitalizations 6 months before IH were associated with potentially preventable medication-related readmissions within 30 days.

It would be interesting to explore the association between the clinical presentation during previous hospitalizations and this presentation during the preventable medication-related readmission. Possibly, adverse drug events were already present during the previous hospitalizations and index admission, but not recognized by the caregivers. As also

TABLE 3 | Type and subtype of medication errors involved in potentially preventable medication-related readmissions.

\begin{tabular}{llc}
\hline Type of error & Subtype of error & $\boldsymbol{n}(\%)$ \\
\hline Prescribing & & $25(35)$ \\
& Underprescribing & $10(40)$ \\
& Dosage & $6(24)$ \\
& Inadequate monitoring & $5(20)$ \\
& No indication & $3(12)$ \\
Across settings & Contraindication & $1(4)$ \\
Medication use & Transition errors & $22(30)$ \\
& Non-adherence & $25(35)$
\end{tabular}


described by Ravn-Nielsen et al. some Emergency Department visits or (re)admissions are not obviously medication-related (Ravn-Nielsen et al., 2018). If patients present themselves at the Emergency Department due to non-adherence, this will typically manifest itself as a worsening of his or her underlying disease and only if the patient indicates to be non-adherent this will be recognized as an adverse drug event. Apparently, in most cases the patient will be discharged without solving the adverse drug event, which could result in (re)admissions. Antidiabetics, diuretics, laxatives, antithrombotic agents and medications for asthma/COPD were most frequently involved. These agents correspond to medicines associated with medication-related admissions (Leendertse et al., 2008).

Although this is the first study to describe an extensive assessment of the prevalence and preventability of unplanned medication-related readmissions, it does have some limitations. First, this was a single-centre study and only the wards with the highest readmission rates in previous years were included, limiting the generalizability. However, reviewing files of readmitted patients is resource-intensive and so the selection of high-risk departments increased the focus of reviewers. Second, we used a two-step approach (resident review and confirmation by senior internist and hospital pharmacist) to assess the prevalence and preventability of medication-related readmissions. Some medication-related readmissions could have been missed if they were not recognized in the first step by the residents. However, our approach is likely to result in high specificity, which increases the reliability of the results. Third, during this study a TPC-program was implemented. As this program tends to improve the transfer of medication-related information to the patient and next healthcare providers, it is possible that it resulted in less medication related readmissions. Finally, the preventability of medication-related readmissions was assessed using information from medical records and adherence information based on the medication history. Relevant information from the patient or primary care providers not documented in the medical records could have been missed: for example, non-adherence due to practical problems or adverse drug reactions, leading to a higher preventability in reality. Furthermore, we examined nonadherence based on refill rates, which does not establish whether a patient actually uses his medication. However, the value of using refill rates in clinical research has been shown (Arnet et al., 2016).

\section{REFERENCES}

Ahmad, A., Mast, M. R., Nijpels, G., Elders, P. J., Dekker, J. M., Hugtenburg, J. G., et al. (2014). Identification of drug-related problems of elderly patients discharged from hospital. Patient Prefer Adherence 8, 155. doi:10.2147/PPA.S48357

Arnet, I., Kooij, M. J., Messerli, M., Hersberger, K. E., Heerdink, E. R., Bouvy, M., et al. (2016). Proposal of standardization to assess adherence with medication records: methodology matters. Ann. Pharmacother. 50, 360-368. doi:10.1177/ 1060028016634106

El Morabet, N., Uitvlugt, E. B., van den Bemt, B. J. F., van den Bemt, P., Janssen, M. J. A., Karapinar-Carkit, F., et al. (2018). Prevalence and preventability of drug-
In summary, this study shows that $16 \%$ of the readmissions are caused by medication, of which $40 \%$ are potentially preventable. If the results are confirmed in larger multicentre studies, this may indicate that more attention should be paid to medication-related harm as a cause of readmissions in order to lower the overall readmission rates.

\section{DATA AVAILABILITY STATEMENT}

The raw data supporting the conclusions of this article will be made available by the authors, without undue reservation.

\section{ETHICS STATEMENT}

The study was approved by the local review board of the hospital (Advies Commissie Wetenschappelijk Onderzoek Medische Ethische Commissie, ACWO-MEC; registration number 16-028). Patient data were obtained and handled in accordance with privacy regulations.

\section{AUTHOR CONTRIBUTIONS}

FK-Ç designed the study. EU, MJ, CS, EK collected and reviewed the data. EU, Bv, Pv, FK-Ç analysed and interpreted the data. EU, MJ, CS, EK, Bv, Pv, FK-Ç, drafted the article.

\section{ACKNOWLEDGMENTS}

We are grateful to the doctors of all departments for their help during the study and to students Najla el Morabet, Samira Boujarfi, Ninora Korkis and Wai-Lung Chung for data collection. Special thanks go to Albertine van der Does for data collection and support, and also to Tjeerd van de Ploeg and Joost Vanhommerig for their statistical advice.

\section{SUPPLEMENTARY MATERIAL}

The Supplementary Material for this article can be found online at: https://www.frontiersin.org/articles/10.3389/fphar.2021.567424/ full\#supplementary-material.

related hospital readmissions: a systematic review. J. Am. Geriatr. Soc. 66, 602-608. doi:10.1111/jgs.15244

Feigenbaum, P., Neuwirth, E., Trowbridge, L., Teplitsky, S., Barnes, C. A., Fireman, E., et al. (2012). Factors contributing to all-cause 30-day readmissions: a structured case series across 18 hospitals. Med. Care 50, 599-605. doi:10. 1097/MLR.0b013e318249ce72

Garcia-Caballos, M., Ramos-Diaz, F., Jimenez-Moleon, J. J., and Bueno-Cavanillas, A. (2010). Drug-related problems in older people after hospital discharge and interventions to reduce them. Age Ageing 39, 430-438. doi:10.1093/ageing/afq045

Jencks, S. F., Williams, M. V., and Coleman, E. A. (2009). Rehospitalizations among patients in the Medicare fee-for-service program. N. Engl. J. Med. 360, 1418-1428. doi:10.1056/NEJMsa0803563 
Karapinar-Çarkit, F., Borgsteede, S. D., Zoer, J., Egberts, T. C., van den Bemt, P. M., and Tulder, M. v. (2012). Effect of medication reconciliation on medication costs after hospital discharge in relation to hospital pharmacy labor costs. Ann. Pharmacother. 46, 329-338. doi:10.1345/aph.1Q520

Kardas, P., Lewek, P., and Matyjaszczyk, M. (2013). Determinants of patient adherence: a review of systematic reviews. Front. Pharmacol. 4, 91. doi:10.3389/ fphar.2013.00091

Kramer, M. S., Leventhal, J. M., Hutchinson, T. A., and Feinstein, A. R. (1979). An algorithm for the operational assessment of adverse drug reactions. I. Background, description, and instructions for use. Jama 242, 623-632. doi:10.1001/jama.242.7.623

Lau, P. M., Stewart, K., and Dooley, M. J. (2003). Comment: hospital admissions resulting from preventable adverse drug reactions. Ann. Pharmacother. 37, 303-305. doi:10.1177/106002800303700229

Leendertse, A. J., Egberts, A. C., Stoker, L. J., and van den Bemt, P. M. (2008). Frequency of and risk factors for preventable medication-related hospital admissions in The Netherlands. Arch. Intern. Med. 168, 1890-1896. doi:10. 1001/archinternmed.2008.3

McDonnell, P. J., and Jacobs, M. R. (2002). Hospital admissions resulting from preventable adverse drug reactions. Ann. Pharmacother. 36, 1331-1336. doi:10. 1345/aph.1A333

Mueller, S. K., Sponsler, K. C., Kripalani, S., and Schnipper, J. L. (2012). Hospitalbased medication reconciliation practices: a systematic review. Arch. Intern. Med. 172, 1057-1069. doi:10.1001/archinternmed.2012.2246

Parekh, N., Ali, K., Page, A., Roper, T., and Rajkumar, C. (2018). Incidence of medication-related harm in older adults after hospital discharge: a systematic review. J. Am. Geriatr. Soc. 66, 1812-1822. doi:10.1111/jgs.15419

Quan, H., Li, B., Couris, C. M., Fushimi, K., Graham, P., Hider, P., et al. (2011). Updating and validating the Charlson comorbidity index and score for risk adjustment in hospital discharge abstracts using data from 6 countries. Am. J. Epidemiol. 173, 676-682. doi:10.1093/aje/kwq433

Ravn-Nielsen, L. V., Duckert, M. L., Lund, M. L., Henriksen, J. P., Nielsen, M. L., Eriksen, C. S., et al. (2018). Effect of an in-hospital multifaceted clinical pharmacist intervention on the risk of readmission: a randomized clinical trial. Jama Intern. Med. 178, 375-382. doi:10.1001/jamainternmed.2017.8274

Reynolds, M., Hickson, M., Jacklin, A., and Franklin, B. D. (2014). A descriptive exploratory study of how admissions caused by medication-related harm are documented within inpatients' medical records. BMC Health Serv. Res. 14, 257. doi:10.1186/1472-6963-14-257

Rosen, O. Z., Fridman, R., Rosen, B. T., Shane, R., and Pevnick, J. M. (2017). Medication adherence as a predictor of 30-day hospital readmissions. Patient Prefer Adherence 11, 801. doi:10.2147/PPA.S125672

Rothwell, M., Jukka, C., Lum, E., Mitchell, C., and Kyriakides, P. (2011). Retrospective analysis of emergency readmissions to rural and regional hospitals. J. Pharm. Pract. Res. 41, 290-294. doi:10.1002/j.2055-2335.2011. tb00106.x
Ruiz, B., García, M., Aguirre, U., and Aguirre, C. (2008). Factors predicting hospital readmissions related to adverse drug reactions. Eur. J. Clin. Pharmacol. 64, 715-722. doi:10.1007/s00228-008-0473-y

Sabaté, E. (2003). Adherence to long-term therapies: evidence for action. World Health Organization. Accessed at: https://apps.who.int/iris/bitstream/handle/ 10665/42682/9241545992.pdf (Accessed November 27, 2019).

Schumock, G., and Thornton, J. (1992). Focusing on the preventability of adverse drug reactions. Hosp. Pharm. 27, 538.

Steyenberg, E. W. (2009). Clinical prediction models: a practical approach to development, validation, and updating statistics for biology and Health. Bio. Metric. J. 62, 1122-1123. doi:10.1007/978-3-030-16399-0

van den Bemt, P. M., and Egberts, A. (2007). Drug related problems: definitions and classification. EJHP Pract. 13 62-64.

van der Does, A. M., Kneepkens, E. L., Uitvlugt, E. B., Jansen, S. L., Schilder, L., Tokmaji, G., et al. (2020). Preventability of unplanned readmissions within 30 days of discharge. A cross-sectional, single-center study. PLoS one 15, e0229940. doi:10.1371/journal.pone.0229940

van Doormaal, J. E., Mol, P. G., van den Bemt, P. M., Zaal, R. J., Egberts, A. C., Kosterink, J. G., et al. (2008). Reliability of the assessment of preventable adverse drug events in daily clinical practice. Pharmacoepidemiol. Drug Saf. 17, 645-654. doi:10.1002/pds.1586

Van Walraven, C., Bennett, C., Jennings, A., Austin, P. C., and Forster, A. J. (2011). Proportion of hospital readmissions deemed avoidable: a systematic review. Cmaj 183, E391-E402. doi:10.1503/cmaj.101860

Warlé-van Herwaarden, M. F., Valkhoff, V. E., Herings, R. M., Engelkes, M., van Blijderveen, J. C., Rodenburg, E. M., et al. (2015). Quick assessment of drugrelated admissions over time (QUADRAT study). Pharmacoepidemiol. Drug Saf. 24, 495-503. doi:10.1002/pds.3747

World Health Organization (2006). Definitions Available at: https://www.who.int/ medicines/areas/quality_safety/safety_efficacy/trainingcourses/definitions.pdf (Accessed November 27, 2019).

World Health Organisation (2019). Medication safety in transitions of care. Available at: https://apps.who.int/iris/bitstream/handle/10665/325453/WHOUHC-SDS-2019.9-eng.pdf?ua=1 (Accessed November 27, 2019).

Conflict of Interest: The authors declare that the research was conducted in the absence of any commercial or financial relationships that could be construed as a potential conflict of interest.

Copyright $\odot 2021$ Uitvlugt, Janssen, Siegert, Kneepkens, van den Bemt, van den Bemt and Karapinar-Çarkit. This is an open-access article distributed under the terms of the Creative Commons Attribution License (CC BY). The use, distribution or reproduction in other forums is permitted, provided the original author(s) and the copyright owner(s) are credited and that the original publication in this journal is cited, in accordance with accepted academic practice. No use, distribution or reproduction is permitted which does not comply with these terms. 